\title{
EL MOVIMIENTO POSTUMISTA: ENFOQUE FILOSÓFICO 100 AÑOS DESPUÉS
}

\section{The postumist movement: a philosophical approach 100 years later}

\author{
Julio Minaya Santos \\ Profesor Titular de la Universidad Autónoma de Santo Domingo (UASD), Santo Domingo, Repúblcia Dominicana. \\ ORCID: 0000-0001-8915-6308, Correo-e: julminaya@gmail.com
}

Recibido: 4/9/2021 • Aprobado: 15/10/2021

Cómo citar: Minaya Santos, J. (2021). El movimiento postumista: enfoque filosófico 100 años después. Ciencia y Sociedad, 46(4), 113-130. Doi: https://doi.org/10.22206/cys.2021.v46i4.pp113-130

\section{Resumen}

El artículo realiza un enfoque filosófico sobre el movimiento poético y literario postumista, con motivo de celebrarse este año 2021 el centenario de su Manifiesto en Santo Domingo. Se parte de cuatro núcleos teóricos principales: sensibilidad estética, ética poética, realce axiológico de lo propio y búsqueda de autonomía intelectual. El Postumismo significó un movimiento de vanguardia que dio un giro a la forma tradicional de concebir la obra poética, conforme se abandona el axioma clasicista en que rima y ritmo representaban condiciones sine qua non para validar dicho género literario. Al acuñar la expresión "acento emocional" como categoría estética, la escuela postumista abre un horizonte para una comprensión nueva del fenómeno poético, donde las palabras pierden relevancia frente al rol preponderante del tono emocional. El postumismo puso a la poesía, y luego a todo arte literario, a cantarle a la vida cotidiana, a la naturaleza, a lo autóctono. Además, propugnó la autonomía del pensamiento y la conversión de la poesía y del arte en sentido general, en una base esencial para embellecer y dignificar la vida humana. De ahí que la importancia del postumismo no radique únicamente dejar como legado la primera escuela poética y literaria surgida en República Dominicana, sino también en su apuesta por una mayor valoración material y espiritual del pueblo dominicano y Latinoamérica.

Palabras clave: literatura dominicana, postumismo, filosofía, autonomía intelectual.

\begin{abstract}
The purpose of this article is to carry out a philosophical approach on the postumist poetic and literary movement, given the commemoration, this year 2021, of the centenary of its Manifesto in Santo Domingo. It starts from four main theoretical nuclei: aesthetic sensitivity, poetic ethics, axiological enhancement of one's own and search for intellectual autonomy. Postumism meant a movement of experimental ideas that changed the direction of the traditional way of conceiving the poetic work, as the classicist axiom in which rhyme and rhythm represented sine qua non conditions to validate said literary genre was abandoned. By coining the expression "emotional accent" as an aesthetic category, the postumist school opens a horizon for a new understanding of the poetic phenomenon, where words lose relevance before the preponderant role of the emotional tone. Postumism put poetry, and later all literary art, to sing to daily life, to nature, to the autochthonous. Furthermore, postumism advocated for a free and individual reflection and the conversion of poetry and art in a general sense, in an essential basis for embellishing and dignifying human life. Consequently, the importance of postumism lies not only in leaving as a legacy the first poetic and literary school that emerged in the Dominican Republic, but also in its commitment to a greater corporeal and spiritual appreciation of the dominican people and Latin America.
\end{abstract}

Keywords: Dominican literature, postumism, philosophy, intellectual autonomy. 


\section{Introducción}

La hazaña poética del movimiento postumista, incomprendido como toda iniciativa cultural refractaria a la tradición, significó tanto un movimiento de rebeldía artístico-literario como un gesto contestario de carácter intelectual e ideológico. Concebirlo y gestarlo conllevó un denodado esfuerzo artístico e intelectual. Tal constatación permite sustentar la tesis de que el postumismo, en tanto escuela póetico-literaria, asume una serie de componentes teóricos que le sirvieron de orientación y fundamentación, los cuales pueden ser estudiados desde un punto de vista histórico-filosófico. El presente trabajo tiene como motivación fundamental dilucidar dicha cuestión.

Por el contexto político, histórico y sociocultural en que se gesta, caracterizado por la ocupación foránea del país y una profunda crisis mundial tras la guerra del 14, la nueva escuela significó un proyecto muy cónsono con mentes juveniles. Efectivamente, Domingo Moreno Jimenes escribe sus primeros poemas de aliento postumista, sin rima ni metro para distanciarse del clasicismo, a los 22 ańos. "Promesa" y "Vuelos y duelos" marcan el comienzo. Andrés Avelino tiene 20 cuando escribe Fantaseos. El de mayor edad en la "Trilogía poética", Rafael Augusto Zorrilla, sumaba 29 años. Su rol preponderante, no obstante ser poeta, fue servir de estímulo y apoyo a la nueva tendencia poética y literaria, cuyos postulados compartía.

La creación y promoción del postumismo estuvo presidido por un vigoroso espíritu de vanguardia, para lo cual se requirió de una alta dosis de cordura e inteligencia, así como de una tenacidad especial proveniente de la idiosincracia artística de sus patrocinadores. A ello debe agregarse la sólida formación teórica facilitada por selectos cuadros de la escuela hostosiana, en cuyos hombros descansó su educación formal.

Todo lo anterior, con ser bastante, no permite explicar los logros cosechados por la propuesta postumista. Debe mencionarse también la exigente disciplina implicada en los esfuerzos autodidácticos desplegados por las dos cabezas mejor organizadas de la trilogía. Es la conjugación de estos elementos lo que permite explicar la precoz madurez intelectual que se aprecia tanto en el fundador del postumismo como en el redactor de su Manifiesto, de quienes hemos heredado legados paradigmáticos, tanto en el campo de la literatura como del pensamiento filosófico en República Dominicana.

La indagatoria en torno a los supuestos teóricos y propósitos de la Escuela Postumista, supone examinar no solo la declaración de Andrés Avelino que ocupa las últimas seis páginas del aludido libro Fantaseos, publicado por Avelino en 1921, sino, además, el otro documento fundacional de nueve páginas, redactado por Moreno Jimenes, que incorpora como "Preliminar" a la obra. También ha conllevado el estudio de diversos trabajos de la producción poética de Moreno Jimenes, que incluye su obra en prosa Evangelio americano, de 1942.

\section{Enfoque teórico-metodológico}

Desde el punto de vista metodológico el presente esfuerzo investigativo sigue las herramientas teórico-conceptuales y estrategias del enfoque histórico-filosófico, pues se basa en lectura, análisis e interpretación documental y bibliográfica, como procedimientos para elaborar conclusiones o síntesis sobre el tema objeto de investigación. Como propuesta poético-literaria, el postumismo es susceptible de un tratamiento o examen de tipo filosófico, en el cual es posible identificar tanto sus supuestos teóricos como los principios básicos que le dieron origen y fundamentación.

Así como existe una filosofía del arte emparentada con la estética, también se tiene una filosofía de la literatura y, más específicamente, una filosofía de la poesía. Dentro de la historia del quehacer poético local se tienen los casos de Andrés Avelino, Antonio Fernández Spencer y José Mármol como auténticos poetas filósofos o filósofos poetas. 
Para el abordaje del problema se han empleado cuatro ejes básicos, que son: la cuestión de la sensibilidad estética, el tema de la eticidad poética, el asunto axiológico o valoración de lo propio (local y regional) y el problema de la autonomía intelectual. Los restantes tópicos o aspectos esbozados persiguen complementar las coordenadas referidas, ya para garantizar una apropiada contextualización de los temas centrales o bien para introducir informaciones de tipo biográfico que favorezcan una mayor comprensión del postumismo en tanto fenómeno poético y literario, ventilado desde una óptica filosófica.

\section{Domingo Moreno Jimenes en busca de un nuevo horizonte estético}

Domingo Moreno Jimenes nace en Santiago de los Caballeros el 7 de enero de 1894. Una vida saludable y longeva dedicada a la poesía, le permitió legar una sólida y brillante obra, excepcional dentro de nuestro parnaso y de la literatura nativa en general. Mente creadora y líder del postumismo desde sus inicios hasta su deceso el 21 de septiembre de 1986. Moreno Jimenes visualiza muy tempranamente lo que tuvo a bien ponderar como "el ideal estético (...) de mi última modalidad artística" (García, 1921, p. 5). Abrigaba la convicción de que su escuela propiciaría una nueva sensibilidad estética dentro de nuestro devenir histórico-literario, marcando un hito, toda vez que trastocó los cánones del clasicismo y proveyó nuevos cauces y motivos al ejercicio literario en el lar nativo.

Un componente esencial de la propuesta estética del mentor del postumismo, originado por un notable espíritu de vanguardia, radica en su novedosa forma de conceptualizar lo bello: "Siempre fue mi concepto que la belleza no era cuestión de palabras" (García, 1921, p. 5). ¿Cómo llega a esta conclusión? ¿Dónde radica la calidad de lo bello para él? El poeta aclara parte del proceso complejo en que lo intuitivo y lo racional entran en colaboración para el logro de esta hazaña operada en el campo estético. Así lo explica:
Decidí originar una nueva fórmula lírica en la cual toda la prosodia estuviese basada en un acento emocional que, sustituyendo la rima, contribuyera a darle un influyente caudal de expresión al idioma. Lo conseguí (...); pero yo no me quedé ahí; y casi a continuación produje una poesía enteramente regida por las emociones, donde los prejuicios de forma y fondo desaparecen. (Moreno Jimenes, 1921, p. 6)

Dentro del orbe postumista reinaba una intensa búsqueda por encontrar nueva orientación teórica que conectara con la realidad vernácula, tornándola consciente, enalteciéndola y recreándola por mediación del arte. En cierto modo, había que dejar hablar a las cosas ${ }^{1}$, sin parar mientes en las preceptivas literarias que, a la sazón demandaban métricas y consonancias como rasgos fundamentales del cultivo poético.

\section{Recepción de autores europeos y de la región}

Dentro de la filosofía occidental venían tomando cuerpo varias escuelas de pensamiento que priorizaban el afincamiento en lo terrenal y vital, en lo instintivo e intuitivo. Por supuesto, tales preocupaciones son parte de las propuestas filosóficas de Henri Bergson, Edmund Husserl y Friedrich Nietzsche, portador este último de un discurso estético de gran impacto en Occidente.

\footnotetext{
${ }^{1}$ Era una de las finalidades perseguidas por la fenomenología desarrollada por el filósofo alemán Edmund Husserl en las postrimerías del siglo xix y principios del xx. Emparentada con la lógica, la ontología, la teoría del conocimiento, la ética y la psicología, la fenomenología surge en el seno de la filosofía como un nuevo modelo teórico y metodológico radicalmente opuesto al positivismo y a cualquier tipo de ciencia en que el sujeto desaparece del escenario cognitivo. En América Latina la disciplina fenomenológica jugó un papel de primer rango en la lucha contra el positivismo, con su lema: “¡Volver a las cosas!”. Como puede advertirse, los postumistas sintonizan en parte con dicha orientación filosófica, pues nutren sus composiciones poéticas a partir de las realidades concretas del país, desde el hombre natural, los ríos, las montańas, los árboles, hasta los hechos emprendidos y los objetos construidos en el entorno sociocultural.
} 
Importa señalar al respecto, que:

el filósofo alemán introdujo una revolución en el lenguaje, escribiendo prosa como verso y verso como nadie (...) En este sentido, Nietzsche ha sido el padre del estilo libre: quien ha descubierto el arte del gran ritmo, del gran estilo en el período expresivo del formidable movimiento ascendente y descendente de una pasión sobrehumana y sublime. (Céspedes, 1984, p. 12)

Nietzsche, considerado uno de los pensadores "de la sospecha" ${ }^{2}$, tuvo incidencias en varios autores dominicanos nacidos hacia finales de siglo xIX, cuyas publicaciones vieron la luz a inicios del xx. Entre ellos puede citarse a Joaquín Ulises Alfau (18881917), con sus Cartas a la juventud (1913); también a Pedro Henríquez Ureña, quien necesitando argumentar su postura sobre la obsolescencia del positivismo se acerca a Nietzsche y hasta publica el ensayo Nietzsche y el Pragmatismo en 1910. Por último, se tiene al poeta y ensayista Ricardo Vicente Sánchez Lustrino (1886-1915), quien hará la mayor recepción de las obras de Nietzsche en el país ${ }^{3}$, identificándose casi plenamente con este.

Tomando como base diversos poemas en prosa escritos por SánchezLustrino, tales como "Nostalgia", "Almas que pasan", "Palabras", integrados en su libro Pro-Psiquis, Céspedes concluye (1984, p. 12) que, "Sánchez Lustrino es, contrariamente a lo que sostiene Manuel Rueda en favor de Vigil Díaz con su poema "Arabesco", de 1917, el verdadero renovador de la poesía dominicana”.

\footnotetext{
2 Paul Ricoeur, hacia 1965, acuña la expresión "pensadores de la sospecha” para designar la potencialidad crítica y desveladora de tres autores europeos paradigmáticos que pusieron en tela de juicio los fundamentos "aceptados" en que se basaban las categorías de racionalidad y de verdad. Tales pensadores eran Marx, Nietzsche y Freud.

${ }^{3} \mathrm{El}$ interés por la filosofía nietzscheniana cobraría significativa vigencia en el país. En la década de los 80, José Mármol le dedicaría su tesis de grado y, años más tarde, Luis O. Brea Franco publica dos obras sobre el pensamiento filosófico de Nietzsche.
}

Queda planteada aquí la línea de continuidad entre Sánchez Lustrino y los dos movimientos literarios locales del veinte y del cuarenta, pues al decir de Céspedes (1984,), a Sánchez Lustrino les iban a "seguir más tarde los postumistas y luego los sorprendidos con su 'poesía dominicana con el hombre universal' (...)”. (p. 18)

Aparte de su adhesión a la filosofía nietzscheniana, Sánchez Lustrino defendió en sus textos las ideas socialistas y anarquistas, cerrando fila en la defensa ideológica del proletariado, al tiempo de asumir una moral libre e individualista.

Hasta donde se tiene conocimiento, los postumistas no comulgaban con el marxismo y el nihilismo; sin embargo, no permanecieron de espaldas de otras escuelas de pensamiento que descollaron a finales de siglo XIX e inicios del xx. En cierta forma conectan con los postulados del élan vital expuestos por Henri Bergson en su obra La evolución creadora, de 1907. Se vinculan también con los esfuerzos de encontrar una nueva estética que cubriera el enorme vacío espiritual abierto por un positivismo expirante, del cual son sepultureros varios filósofos latinoamericanos contemporáneos de los postumistas, como Antonio Caso, José Vasconcelos y Alfonso Reyes, de México; incluyendo por supuesto a Pedro Henríquez Ureña ${ }^{4}$, entre otros.

\section{El "acento emocional" del postumismo y su vincu- lación con la teoría estética de Vasconcelos}

Cuando se ahonda en los conceptos básicos en que se fundamenta la teoría estética del postumismo, es inevitable dilucidar la categoría de "acento emocional".

\footnotetext{
${ }^{4}$ Henríquez Ureña tuvo estrechos vínculos de amistad con los tres filósofos mexicanos mencionados, junto a los cuales desarrolló un importante itinerario de trabajo intelectual y académico en México durante el intervalo 1909-1914. Sus efectos benéficos impactaron significativamente el campo educativo, artístico, científico y filosófico de aquella nación, pues luego de la caída del porfiriato sobrevino el ocaso del positivismo, doctrina a la que los ateneístas impugnaron, al tiempo que contribuyeron a llenar el vacío intelectual o teórico que sobrevino.
} 
La emplean tanto Moreno Jimenes como Andrés Avelino en sendos textos integrados en la obra Fantaseos, de este último. Aquí dan cuenta de sus hallazgos en materia poética y artística, y se emplean a fondo por presentar un esbozo de sus concepciones estéticas y filosóficas.

Así, profundizando en torno a su propia experiencia poética, decisivamente novedosa, ambos autores convergen en un nuevo concepto para una nueva escuela, con lo cual se inaugura en esta media isla una manera inédita de entender la experiencia estética que, si bien comienza por la poesía, termina por dotar de sentido cualquier fenómeno vinculado al disfrute artístico, sea en la música, la arquitectura o las artes plásticas, etc. Así pues, la expresión "acento emocional", contrapuesta a "acento periódico", resulta clave para un abordaje filosófico del postumismo, motivo por el cual se le presta una atención particular en el presente trabajo.

Se advierte que en José Vasconcelos, Antonio Caso (filósofos mexicanos) y Pedro Henríquez Ureña, alienta un pathos estético que guarda nexos con las preocupaciones de la escuela postumista. Tal característica se capta sobre todo en la producción teórica legada por José Vasconcelos, en tanto se propone configurar una dimensión estética de la existencia humana. Como afirma Mario Teodoro Ramírez (2011, p. 542):

la estética ha devenido para los modernos y contemporáneos en algo así como una zona franca para el pensar: esa en la que pueden plantearse sin prevenciones aquellos temas y modos de vida que se resisten a quedar en el olvido, o que no tienen cabida en las formas de pensamiento dominantes.

Vasconcelos escribió su obra El monismo estético en 1918, precisamente durante el año en que Moreno Jimenes escribe los poemas originarios del postumismo. Pero con anterioridad Vasconcelos había publicado Prometeo vencedor y Pitágoras, una teoría del ritmo. Puede afirmarse que en lo que atañe a la filosofía, José Vasconcelos era la personalidad que mayor interés concitaba en Latinoamérica para aquel intervalo.

Conocido principalmente por su obra Raza cósmica (1925), Vasconcelos realizaría dos visitas a República Dominicana. En 1926 fue invitado por el gobierno horacista para divulgar el contenido de su obra cimera y exponer su experiencia educativa. Dictó conferencias en cinco ciudades y con toda probabilidad fue escuchado por Moreno, Avelino y demás poetas del postumismo.

Importa señalar que el enfoque monista estético vasconceliano (Sosa Ramos, 2006, s/p):

está fundamento en tres principios o postulados que tienen relación entre sí: la belleza como una forma especial de energía; la emoción estética como condición para comprender a la naturaleza de las cosas; $y$ el Universo, que se fortalece cada vez más, que se hace más bello. [Luego agregará] que para Vasconcelos la emoción o intuición estética es el método para conocer la realidad; el mundo se puede conocer, y a la vez sentir.

Por coincidencia o no, una categoría o expresión característica del discurso postumista es la de acento emocional. Dice Andrés Avelino en el Manifiesto Postumista (1921, p. 55): "nuestro acento emocional permite una mezcla igual de idea y de emoción". Aunque para la época el precoz joven intelectual dominicano no había publicado obras estrictamente filosóficas, ya se perfila su tendencia a considerar las afinidades estrechas existentes entre el saber poético y el conocimiento filosófico, con sus respectivos énfasis en lo emocional y en lo racional, tal como lo concibieron posteriormente Antonio Fernández Spencer y José Mármol, para quienes la poesía y la filosofía no constituyen compartimientos estancos.

\section{La poesía como forma de conocimiento}

Que la poesía encierra la posibilidad de acceder a un determinado tipo de saber es cuestión de consenso, 
especialmente luego de zafarse de la prisión a que la tenían subyugada el racionalismo y el espiritualismo. Hay, como indica Croce, un saber intuitivo estético de cara a la construcción científica, filosófica y religiosa.

Importa traer a colación el planteamiento de José Mármol al respecto. En su libro Ética del poeta (1997, p. 23), explica: "Este conocimiento es particular, en el sentido de que no tiene que representar conceptos o cosas, es decir, referirlos, sino que el lenguaje poético tiene la facultad de fundar conocimientos". La poesía, pues, tiene la facultad de estimular y revelar aspectos desconocidos, y muchas veces escondidos, de la realidad, que otras áreas cognitivas podrían pasar por alto. De ahí la pertinencia del ejercicio poético como generador cognitivo al servicio del ser humano. Mármol ahonda la temática y aclara cómo opera la trama poética en procura de posibilitar el acceso a un nuevo sentido acerca de la realidad:

El poema no reproduce lo que es visible, sino que en su mediación discursiva, en su autogénesis como síntesis superadora hace que lo visible se pluralice en la integridad de su sentido, que se enriquezca, que se haga multívoco, polisémico; que se haga inextenso, es decir, cosa de pensamiento y no cosa de extensión, dicho en lenguaje cartesiano. (Mármol, 1997, p. 32)

Andrés Avelino tiene el mérito de emitir los primeros planteamientos en suelo nativo acerca del nexo existente entre el poetizar y el filosofar, al postular que poetizar es una forma de profetizar, una manera de hacer filosofía. Esto queda aclarado en su Manifiesto: "Los poetas no seguirán siendo seres privilegiados y desconocidos de la multitud, camino del ensueño, sino seres videntes, camino de la verdad, pensadores y filósofos" (García, 1921, p. 53).

Medio siglo más tarde será Antonio Fernández Spencer el autor local que se ocupará de abordar con lucidez la relación poesía-filosofía, en $A$ orillas del filosofar (1960), donde sostiene (2014, p. 42):
No concibo una filosofía que no confunda, aunque sea en parte, su realidad con la de poesía. ¿No son acaso poetas, en su mayoría, los filósofos presocráticos? Cuando la filosofía pierde su adustez de cápsula contentiva de conceptos, se resuelve en poesía. Cuando la poesía aprisiona el ser del complejo ontológico, como sucede frecuentemente en la obra de todo poeta verdadero, ha realizado pura filosofía.

Esta importante temática será reasumida en República Dominicana hacia finales de siglo, a través de varios escritos divulgados por José Mármol, particularmente en la obra ya referida: Ética del poeta (1997).

\section{Ethos del poeta: presencia de una ética poética en el postumismo}

Otro punto a tomar en cuenta dentro de este abordaje filosófico de la escuela postumista se advierte en la declaración de 1921. Se trata de la eticidad poética. El ethos postumista ha sido dimensionado e interpretado tanto teórica como ideológicamente por Andrés Avelino; empero, quien lo encarna o personifica con acendrada vocación de poeta, a lo extenso de toda su vida, es Domingo Moreno Jimenes. No es ocioso enfatizar que el fundador del postumismo vivió siempre por y para la poesía.

A juzgar por sus biógrafos principales, al padre del postumismo no le interesaba dar formalidad teórica a su escuela, sino propiciar el despliegue creativo de cada uno de sus integrantes, con libertad plena al momento de emprender la poiesis, sin fórmulas preconcebidas, para de esta suerte poder dar riendas sueltas al torrente emocional por mediación al lenguaje. Pero contrario a Moreno Jimenes, Avelino apostaba a la formalidad y a la mayor proyección posible del movimiento. Por eso se impuso la tarea de redactar el documento para su lanzamiento formal, sin recurrir al necesario consenso sobre su alcance y contenido. De ahí que solo aparezca su firma en la declaratoria del final de su libro previamente mencionado: Fantaseos. Y que la postura de Moreno 
Jimenes, de gran enjundia también, aparezca al inicio del libro, firmada por él solamente. Se trata, bien vistas las cosas, de textos complementarios. La declaración de Avelino solo logra entenderse íntegramente con una lectura sosegada del escrito de Moreno Jimenes.

En cuando a la denominación del movimiento, José Rafael Lantigua explica (1980, p. 65): "Consolidado el grupo se pensó buscarle nombre a la agrupación lírica. A Moreno le sugirieron varios nombres, hasta que aceptó uno propuesto por Avelino: Postumismo". La designación sugiere que sería conocido y valorado después de la muerte del fundador y sus promotores; por tanto, nace con vocación de futuro y no se espera validación o reconocimiento en el tiempo presente. Hay, pues, una clara conciencia de que la valoración adecuada del proyecto tendría significado póstumo.

En sendos libros sobre el autor y el postumismo, José Rafael Lantigua y Bárbara Moreno García ${ }^{5}$, profundizan este arraigo pasional y misional del poeta, con lo cual logran poner de manifiesto, aparte de su intensa dedicación escritural, el ímprobo trabajo de promoción efectuado por el padre del postumismo través de talleres y conferencias destinados a estimular el arte poético y literario entre la juventud diseminada por las principales ciudades dominicanas.

Ha de subrayarse otro aspecto relevante de su vida literaria y poética: aparte de su trabajo como educador $^{6}$, en varias etapas de su vida los ingresos para la manutención familiar provinieron de la venta

\footnotetext{
${ }^{5}$ Ambos autores, cuyos libros aparecen en la lista de referencias bibliográficas, se dedican íntegramente al estudio de la vida y la obra de Domingo Moreno Jimenes. Otra obra recomendada es Antología poética de Domingo Moreno Jimenes (1999), citada en este artículo, por dar a conocer en 38 páginas importantes datos y posturas críticas en torno al poeta y su vida.

${ }^{6}$ Estudia en la Escuela de Bachilleres que, a la sazón, era la Escuela Oficial, dirigida por Federico Henríquez y Carvajal. Allí obtiene el diploma de "Maestro Normal" de Segunda Enseńanza. Además de educador, Moreno Jimenes fue director de varios centros escolares.
}

de sus libros, que realizaba personalmente desplazándose incluso por pueblos del interior. Dado que ello coincidió con la dictadura de Trujillo, tal forma de ganarse la vida pudo constituir la única alternativa para gozar de cierto margen de independencia, lo cual habría sido imposible conseguir de ostentar alguna función pública. ${ }^{7}$ Se advierten en Moreno ribetes evidentes de un acentuado ascetismo, hijo del compromiso ético con que encaró siempre su vocación de poeta, por lo que muchos lo han estimado como un arquetipo dentro del parnaso nacional.

En su esbozo de una ética poética, José Mármol (1997, p. 11), hace una importante precisión: "El poeta tiene, pues, una misión, y no precisamente una función (...) Esa misión profetizante encierra una responsabilidad, quiero decir, un principio de honestidad". En el caso de Moreno se trata de una honestidad que se extiende y profundiza con otra virtud que le es afín: la sinceridad o, por mejor decir: autenticidad. En él se advierte una "vida sincera e íntima" como bien postula Avelino en su proclama del 21, evocando, probablemente, al "hombre sincero" y natural al que cantó José Martí.

\section{Valoración de lo propio y contribución de Andrés Avelino al postumismo}

Este abordaje filosófico del postumismo se ocupa también de su costado axiológico, puesto de manifiesto en la producción poética postumista y en su Manifiesto. Su afincamiento en los temas locales y el hecho de dar expresión a los elementos de la vida cotidiana con un lenguaje sencillo y cercano a la gente, le cosechó a los postumistas el rechazo de muchos que restaban validez estética y literaria a sus producciones poéticas. Fue el caso de Patín Maceo, quien llegó a considerar dicha corriente (como se citó en Manuel Rueda), "el pozo negro de la literatura dominicana".

\footnotetext{
${ }^{7}$ Lo afirmado cobra validez si se tiene en cuenta que jóvenes de preclaras condiciones literarias e intelectuales, como Juan Bosch, Pedro Mir y Juan Isidro Jimenes Grullón, este último primo hermano de Moreno Jimenes, tuvieron que abandonar el país.
} 
Tratar el tema del valor conferido a lo dominicano, enlaza con el criollo Antonio Sánchez Valverde ${ }^{8}$, quien presenta el primer muestrario de lo que representa la isla como tesoro natural, geográfico, económico y hasta etnológico. Su obra Idea del valor de la isla Española (1785) cumple ese cometido. Luego de Sánchez Valverde se tiene a Pedro Francisco Bonó como el autor que estudia con mayor interés la territorialidad, el axio, el ethos y el onto vinculado al pueblo dominicano, durante la segunda mitad de la centuria decimonónica.

Luego de ese periodo, $\mathrm{y}$ de inicios de siglo $\mathrm{xx}$, datan los escritos de José Joaquín Pérez y de Arturo Pellerano Castro, entre otros autores, los cuales se caracterizan por sus planteamientos en favor de la literatura criollista. Todo lo cual funciona como antecedencia de las preocupaciones de la tríada poética impulsadora del ideal postumista.

Al decir de Avelino, en el postumismo habrá de cultivarse el "arte autóctono para abrir la talanquera que nos ha separado del infinito" (García, 1921, p. 52). Con la asunción de temas nativos en la poesía y el arte se podrían potenciar creaciones de trascendencia universal.

Es oportuno destacar que dentro del círculo postumista no se desdeńa la literatura o el arte europeo a ultranza, pues como apunta Henríquez Ureña (2003, p. 403), "nuestras tierras, nuestra vida libre, pedían su expresión", pero además "fracasada Europa, hemos descubierto que los Estados Unidos tienen muy poco de suyo que enseñar" (Henríquez Ureña, 2003, 401). Son ideas de 1923, a dos años de proclamarse la insurrección literaria postumista. Para Avelino, los más excelsos representantes europeos son "soles apagados

\footnotetext{
${ }^{8}$ Este autor, aparte de ser considerado el padre del criollismo dominicano, tal como lo consignan Miguel de Camps Jiménez (El criollo Antonio Sánchez Valverde. Su época, su vida, su obra (2014, pp. 44-55), y Roberto Cassá (“Antonio Sánchez Valverde. Intelectual del criollismo", en Personajes dominicanos, T. I (2013, pp. 25-47), ha de ser tenido también como el precursor de la filosofía dominicana, gracias a su Carta al Conde de San Xavier, publicada en Caracas en 1770.
}

que no nos iluminarán" (1921, p. 52). De ahí que para Henríquez Ureña (2003, p. 399):

Nunca como ahora necesita la América Latina normas, orientaciones, nuevo espíritu, definición de su vida propia. Nunca como ahora necesita dirección (...) La crisis de la civilización moderna, que se inicia en 1914 y se agrava día a día, ha dejado huérfana, espiritualmente, a nuestra América (...) Hasta ayer, Europa había sido la maestra; a ella le pedíamos la doctrina y la moda, el método y la máquina.

La expresión "Nuestra América", justamente empleada en El Manifiesto por Avelino, se hizo famosa en el continente desde la publicación en 1891 del célebre ensayo homónimo de José Martí, donde exhortaba vehementemente a crear desde lo más íntimo del ser latinoamericano: "Ni el libro europeo, ni el libro yankee, daban la clave del enigma hispanoamericano (...) Crear es la palabra de pase de esta generación. El vino, de plátano, y si sale agrio, es nuestro vino" (Martí, 1993, p. 125).

Las influencias martianas y de Henriquez Ureña entre los postumistas es inequívoco. Se advierten, incluso, expresiones muy parecidas entre lo escrito por Martí y lo expresado por Avelino. El poeta y ensayista cubano indica que lo que habrá de enseñarse a nuestros jóvenes no son "los arcontes de Grecia. Nuestra Grecia es preferible a la Grecia que no es nuestra. Injértese en nuestras repúblicas el mundo, pero el tronco ha de ser el de nuestras repúblicas" (Martí, 1993, p. 123).

Parejamente, Avelino advierte: "Los mármoles de Paros y de Corinto no se han hecho para nuestras estatuas. No tendremos en nuestros calderos surrapa de Verlaine ni de Mallarmé, de Tristan ni de Laforgue" (García, 1921, pp. 51-52).

Debe consignarse, por otra parte, que la influencia de José Enrique Rodó y su obra Ariel, con enorme presencia en el ambiente intelectual de inicios de siglo xx, ya declinaba para los albores de la corriente postumista, pues diversos autores: 
empiezan a considerar trasnochados y decimonónicos los ideales del "arielismo" y necesitados de orientación y transformación. Se le acusará a Rodó de demasiado europeísta, abstracto e idealista, desconocedor de la causa indígena (...) El crítico más significativo fue el cubano Roberto Fernández Retamar, con el libro que titula Calibán, en el que proponía un nuevo modelo de identidad latinoamericana desde la perspectiva del "hombre natural", esto es, del "mestizo autóctono”. (Beorlegui, 2010, p. 379)

El postumismo tiene su gestación en el contexto de la oprobiosa ocupación estadounidense de 1916, prolongada hasta 1924. Huelga aclarar, por otra parte, que dicha escuela literaria exhibió muestras significativas previo al año de su declaración en 1921, ya que los brotes poéticos primigenios de aliento postumista datan de 1918 y emergen, por supuesto, de la pluma de Domingo Moreno Jimenes.

\section{El postumismo como búsqueda de autonomía intelectual}

Otro de los ejes que ha servido de orientación al presente enfoque filosófico del postumismo es la autonomía intelectual. Es de dominio común que, dentro de la historia de las ideas del orbe hispanoamericano, la lucha por la emancipación política contra la Corona española no conllevó transformaciones en la vida económica, social y cultural de los nuevos países. La autonomía política no trajo consigo la independencia cultural o del pensamiento; tan solo se alcanzó la liberación política. Como ha consignado Leopoldo Zea (1976, p. 68), "La autonomía del intelecto fue la nueva bandera". Se debía abandonar el fardo de creencias y tradiciones que evocara la sociedad colonial.

En lo que atañe a República Dominicana, Pedro Fco. Bonó es el primer autor en reclamar la liberación mental y cultural, exhortando a superar los resabios de la mentalidad heredada de la Colonia, lo cual lleva a cabo en el opúsculo Apuntes sobre las clases trabajadoras dominicanas (1881) y otros escritos. Luego irrumpe Hostos con el accionar exitoso de la Escuela Normal, marcando el segundo jalón de dicho proceso de liberación cultural, al impugnar vehementemente las herencias culturales del régimen colonial español, que implicaba, claro está, el enjuiciamiento de la escolástica como doctrina filosófica y teológica.

Moreno Jimenes y Andrés Avelino se formaron dentro del clima mental de la escuela hostosiana, afincada principalmente en el positivismo. Sin embargo, hacia 1921 ambos forman parte del movimiento regional que propugna el abandono de dicha doctrina, comulgando con el núcleo antipositivista mexicano, donde sobresalen Antonio Caso, José Vasconcelos, Samuel Ramos y Pedro Henríquez Ureña.?

Las corrientes filosóficas que permitieron superar definitivamente el positivismo en la generación de 1915, según Carlos Beorlegui (2010, p. 403):

serán la fenomenología de Husserl y el existencialismo de Heidegger, el historicismo de W. Dilthey, el raciovitalismo de Ortega y Gasset (en sus fases primeras de su circunstancialismo y perspectivismo), y el marxismo (como es el caso de J. C. Mariátegui).

Aunque previamente la hegemonía filosófica positivista ya había sido enjuiciada por Bergson, Nietzsche, Croce, entre otros filósofos.

La decadencia del positivismo ocurre en República Dominicana concomitantemente con la ocupación militar estadounidense de 1916. Ambos fenómenos, aunque diferentes entre sí, incidieron en el estado de ánimo de la juventud intelectual del momento. En tal sentido cobran validez los planteamientos de Pedro Henríquez Ureña desde Estados Unidos, país donde ejercía de profesor hacia 1922:

una colonia es (...) una cosa sin alma, sin alma propia: sus modelos los recibe de la metrópoli.

\footnotetext{
${ }^{9}$ Aunque dominicano, Henríquez Ureña estudió y trabajó como profesor en México durante varios años, país al que hizo notables contribuciones, tanto en el ámbito educativo como intelectual.
} 
Los que no hayan vivido en un pequeño país independiente no conocen el sentimiento que existe en ellos de estar elaborando su propia vida, creando su propio tipo y modo de ser, creando constantemente. Cada nación pequeña tiene alma propia y lo siente. (2003, p. 336)

En la obra Fantaseos, donde se sientan las bases teóricas e ideológicas del postumismo, Avelino, en fiel sintonía con lo manifestado por Henríquez Ureña, expresa el sentimiento que le abate tras enterarse de la suerte corrida por Cayo Báez, campesino cibaeño que enfrentó a las tropas estadounidenses, a quien le compuso un poema:

La hueste devastadora se aproxima

Cae sobre la paz impoluta de la aldea

el bochorno de la barbarie.

El suelo se sonroja con el esputo

de una lengua extranjera

El sol esquiva su faz tras de la loma.

El paisaje enmudece

Las madres lloran.

Los chicuelos huyen medrosos

(García, 1921, pp. 37-38).

Puede afirmarse que el Postumismo constituyó una gesta; obviamente no política o militar sino literaria, poética o, mejor dicho, una guerrilla emprendida por poetas que, como se sabe, son los únicos que tienen la capacidad de disparar con versos.

En el país ya se tenía el precedente de Fabio Fiallo, autor de "Canciones de la tarde" que, como apunta Ylonka Nacidit Perdomo (2015, s/p), por ser un "fiel intérprete de las causas por la libertad de su pueblo, lo pasearon por nuestras calles vestido con el 'palm-beach' (zedra). Fue sometido, además, a la corte prebostal por delitos de prensa”. Otros intelectuales y periodistas fueron ultrajados y conducidos a prisión. Y el entorno postumista no quedaría exento de vejámenes, pues como relata Manuel Mora
Serrano refiriéndose a Domingo Moreno Jimenes (1999, pp. 13-14):

En la segunda semana de marzo de 1920 fue atacado una noche cuando iba a su casa, por un grupo de marines norteamericano que lo golpearon en la calle y lo persiguieron hasta un negocio donde buscó refugio y allí, en medio de risotadas, le dieron patadas y le arrojaron sobre un saco de sal, según relata la revista Letras en su No. 150 del día 14 de dicho mes (...) Ese mismo año, en el mes de noviembre (...) participó en el Primer Congreso de la Prensa Nacional convocado por el poeta Emilio A. Morel (...) suscribiendo las conclusiones que condenaron la Ocupación y pidieron la retirada de los invasores.

Fueron muy difíciles los años en que se gesta el Postumismo $^{10}$. Como describe Juan José Ayuso (Lantigua, 1980, p. 10): "El país se encuentra invadido de norteamericanos por sus cuatro costados (...) Los Evangelistas, Arias y Gilbert se van al monte y empuñan las armas. Domingo Moreno Jimenes pudo encontrarse en una situación difícil". Mora Serrano indica que Moreno prefirió mantener en secreto los vejámenes cometidos en contra de su persona.

A Federico García-Godoy, quien con muchas limitaciones económicas había conseguido editar la obra El derrumbe el mismo año de la ocupación, y ya tenía listas varias cajas en los almacenes de Aduanas para despachar fuera del país, recibió una carta de $\mathrm{F}$. U. Lake, teniente comandante de la Armada de los Estados Unidos, quien expresó al autor, por haber reclamado mediante carta la devolución de las obras: "Muy señor mío:" (García Godoy, 2010, p. 50).

\footnotetext{
${ }^{10}$ Este sombrío panorama ha sido retratado fielmente con las palabras finales del Preliminar que escribiera Moreno Jimenes al libro Fantaseos, al indicar: "Andrés Avelino y Rafael Zoriilla han sido mis inseparables camaradas en estos días de augurios funestos en que el horizonte de las presentes generaciones se ha ensombrencido. Al lado de ellos no he creído una cobardía vivir Sus juveniles entusiasmos cubren de verdor hasta las piedras" (Moreno Jimenes, 1921, p. 13).
} 
Se me hace imposible devolverle la edición de su obra intitulada El Derrumbe, debido a que todos los ejemplares de dicha obra que fueron confiscados en 1916 han sido quemados en cumplimiento de las leyes en vigor. El espíritu de la obra es de una índole tal que puede dar lugar a desórdenes dentro del país, y por ende, su publicación y circulación resultarían contrarias a las disposiciones de las leyes. (GarcíaGodoy, 2010, p. 50)

Federico García-Godoy no era poeta, sino un destacado ensayista ${ }^{11}$ y novelista ${ }^{12}$. La inquisición política del momento ahogó su derecho a expresarse.

Estos hechos forman parte del escenario en que viven y realizan sus creaciones los jóvenes promotores del postumismo. Tuvo razón Baeza Flores al sostener (1976, p. 473): "La primera intervención norteamericana de 1916 produce un despertar de la temática nacional, dominicana, en la poesía, y sin ella no se explican del todo, algunas posiciones y tonos de los poemas postumistas". Esto queda evidenciado cuando se ausculta en la vida personal e intelectual del fundador de la escuela postumista.

El redactor del Manifiesto Postumista tenía bien claro que no podíamos "seguir siendo súbditos de una aristocracia que no nos pertenece. Esta la lleva el pensador en su cerebro" (García, 1921, p. 51). Tal emancipación cultural se expresaría también en

\footnotetext{
${ }^{11}$ En su ensayística son de relevancia sus puntos de vista críticos sobre literatura, filosofía e historia. El Derrumbe sobresale dentro de su producción por enjuiciar una problemática política coyuntural. Cabe destacar que el conjunto de su obra recibió los elogios de figuras cimeras de la intelectualidad latinoamericana, como fueron José Enrique Rodó y Pedro Henríquez Ureña.

${ }^{12}$ De enorme importancia, con el propósito de fomentar el incipiente patriotismo dominicano, García-Godoy concibió tres novelas: Alma dominicana (1911), Guanuma (1914) y Rufinito (1918), conocidas como Trilogía Patriótica de la literatura dominicana. Experimentó los acontecimientos de 1916 como una gran tragedia nacional. Abatido por la impotencia, dejó como testimonio para la posteridad su obra El Derrumbe, la cual, más que una novela constituye un ensayo.
}

los campos del arte y de la literatura, en el sentido de no depender más de formas y estilos del pasado. La nueva escuela quiere desmarcarse incluso de las corrientes romanticista y realista francesas, no exclusivamente del romanticismo inglés o alemán: "Reaccionaremos a la vez contra el romanticismo de Hugo y contra el realismo de Balzac (...) Rubén Darío ha muerto" (García, 1921, p. 54).

La visión filosófica de Moreno Jimenes se encuentra dispersa en varias de sus obras, especialmente en Evangelio Americano $^{13}$, de 1942. Se sabe que su revista El Día Estético, fundada en 1929, órgano de difusión literaria en que colaboraban autores extranjeros, tenía por divisa: "La liberación intelectual del Continente Americano". Hay aquí una clara coincidencia con los ideales emancipadores de Vicente Rocafuerte, Andrés Bello, José Martí, Pedro Fco. Bonó y Eugenio Ma. de Hostos.

\section{Aspectos simbólico-religiosos presentes en el postumismo inicial}

Por otro costado, al indagar en torno al postumismo llama la atención un elemento simbólico: el postumismo estuvo revestido de un contenido ritual, donde se emplean elementos análogos al cristianismo católico. Comenzando por el lugar donde se reunían, la Colina Sacra, que fue al mismo tiempo una casa ${ }^{14} \mathrm{y}$ un cenáculo literario, especie de ciudad simbólica donde los postumistas ejercían plena soberanía, en el marco de un país ocupado militarmente por tropas extranjeras. En los escritos redactados por Moreno Jimenes y Avelino, insertos en la obra Fantaseos de este último, ambos deciden colocar debajo de sus nombres el lugar de: Colina Sacra y

\footnotetext{
${ }^{13}$ Francisco Bilbao, político, literato y pensador chileno, escribió una obra homónima en 1864, donde plantea sus ideas democráticas y emancipadoras"

14 “En 1918 -expresa Moreno Jimenes-, época en que se creó el Movimiento Postumista, yo vivía en Villa Francisca que es una zona muy alta de la Capital (...) y por esta razón uno de los muchachos bautizó mi casa la Colina Sacra” (Piña, 1982, p. 48).
} 
no: Santo Domingo. En realidad, Colina Sacra ${ }^{15}$ funcionaba idealmente al estilo de un "reino independiente". Faltaría indicar que a Moreno Jimenes se le distinguió con un título papal: Sumo Pontifice del postumismo.

Sospechoso de todo movimiento que no tuviera bajo su control, al tirano Rafael L. Trujillo le intrigaba que Moreno Jimenes se desplazara asidua y libremente por muchas ciudades, formando círculos literarios y vendiendo sus libros a jóvenes entusiastas. Para evitar sus incómodas visitas, Trujillo le ofreció un cargo al poeta; pero como alternativa inteligente Moreno le sugirió crear el "Instituto de la Poesía Osvaldo Bazil”, en San Cristóbal. Hubo acuerdo y en 1950 fue creada dicha entidad cultural, en cuya dirección permaneció Moreno Jimenes 20 ańos.

\section{Moreno Jimenes y su intensa militancia ameri- canista}

Contrario a otros literatos dominicanos jóvenes de la época, el fundador del postumismo decidió permanecer en su país; no viajó más que a Puerto Rico ${ }^{16}$ y Haití, pero tenía comunicación con importantes representantes de la literatura y el pensamiento de la región ${ }^{17}$. Mostró cierta simpatía con la política de la izquierda democrática, al punto que Raúl Haya de la Torre le envió una misiva en 1929.

Puede afirmarse, si se compara a Moreno con poetas latinoamericanos de primera línea (Mora Serrano, 1999, p. 30), que: “como Neruda y Vallejo, se afirmó

\footnotetext{
${ }^{15}$ Veinte años luego de haberse creado en la Capital, Moreno Jimenes funda otra Colina Sacra en Santiago de los Caballeros, en su casa de Los Pepines. Y junto a su primo hermano Juan Isidro Jimenes Grullón, funda en Santiago la Universidad Popular y Libre, gratuita, donde fungió como profesor de Estética y Poesía.

16 Viajó en 1941, junto al poeta Franklin Mieses Burgos.

${ }^{17} \mathrm{Su}$ prestigio literario e intelectual se extendió también por España y Estados Unidos. En el primer caso fue invitado por el Instituto de Cultura Hispánica a pronunciar una conferencia, pero no atendió la invitación; en el segundo, el Departamento de Asuntos culturales de "La Unión Panamericana" y la "Ópera Society" de Washington, lo distinguen incluyéndole en la publicación: "Homenaje a los creadores de América Latina".
}

en la tercera década del siglo; como el último, utilizó tonos y frases del argot popular y como ambos, cantaría a las gentes humildes con naturalidad y sería tildado de socialista por ello". Moreno Jimenes dejó entrever su simpatía con la doctrina comunista, pero no al estilo de Marx o Lenin; sino un comunismo espiritualista adaptado a la cosmovisión y principios del judeocristianismo, lo cual podía tomar cuerpo en América ${ }^{18}$, como lo expresa a continuación:

Al comunismo del proletariado, obra de sociedades cansadas y difusas traerá América (...) un comunismo espiritualista, que dividirá los panes y los peces, no al modo de aquellos medios gangrenados sino al de Ntro. Señor Jesucristo. El fracasado de todos los tiempos, el encarnecido por todas las sórdidas guerras en Europa y Asia, en América asomará su cabeza llena de milenarios sueños. Yo veo el Caribe hecho una hoguera inmensa y luces salidas de su fanal en todos los ámbitos del mundo. (Moreno Jimenes, 1973, p. 257)

Moreno conectó con el renovado movimiento americanista que, en la década del 40, y en el contexto de la postguerra, vuelve a radicalizar su postura de abandono de lo europeo, que ya el poeta había adoptado en su etapa juvenil, tras la gran guerra de 1914.

Importa consignar que, a partir de la década del 40, los cultivadores del pensamiento filosófico en Latinoamérica fijan su mirada y confianza en el nuevo pensamiento originado en la región, el cual se irradió desde México bajo el influjo del Grupo Hiperión y de los refugiados republicanos espańoles, en especial

\footnotetext{
${ }^{18}$ Importa señalar que cuando el poeta escribe "América", en ese nombre no incluye a Estados Unidos y Canadá, sino que lo limita a los países latinoamericanos. Para él, los dos países mencionados tienen caracterizaciones culturales diferentes, y hasta opuestas, a los que habitan el Sur. En su óptica de "poeta-profeta", América Latina: mestiza, de "raza cósmica", la "América-Mundo", es la que reviste el conjunto de condiciones para servir como alternativa a una Europa hundida en el colapso total desde los años 40. En realidad, para el autor, Estados Unidos y Canadá constituían una extensión de Europa, y nada nuevo podían representar para el futuro de la humanidad.
} 
José Gaos. Es cuando entra en escena el joven filósofo Leopoldo Zea, junto a otros autores relevantes en la región ${ }^{19}$.

Señala Manuel Mora Serrano (1999, p. 21), que por parte del poeta "Hubo un viaje hacia un americanismo militante que tuvo que ser sofrenado con la aparición de la dictadura trujillista”. Pero debe consignarse que, en el caso de Moreno Jimenes, la dictadura no mermó significativamente dicha militancia, puesto que Moreno tuvo suficiente tacto para ejercerla y promocionarla, tanto a nivel nacional como internacional, sin granjearse hostilidades por parte del tirano. La clave radicó en la forma abstracta, casi mística, en que el autor abordó temas neurálgicos y dispares como el catolicismo y el comunismo.

El influjo americanista en la poesía y el pensamiento de Moreno cobran notable vigencia entre 1936 y 1942. Cuatro son las obras en que se promociona dicha tendencia: Una nueva cosmogonía americana (1936), América-Mundo (1937), La religión de América (1941), en verso, y Evangelio americano (1942), en prosa, donde hace galas de ensayista.

¿Qué lleva a Moreno Jimenes a profesar un americanismo tan "militante"?

Desde la Raza cósmica de José Vasconcelos, se propagó la visión de que en América se había inaugurado un nuevo tipo de ser humano, al cual se le atribuían facultades sui géneris, por su mestizaje biológico y cultural. Sin duda, esto influyó decisivamente en Moreno Jimenes, quien observaba proezas en la región. Así,

\footnotetext{
${ }^{19}$ En lo que respecta a la corriente americanista entre 1940 y 1960, fuera de Moreno Jimenes, en el área de la filosofía los dos autores nativos que tuvieron mayor vinculación fueron Juan Francisco Sánchez y Armando Cordero. Ambos autores no solo lo refieren en sus diversas obras, sino que orientaron su accionar teórico conforme a sus postulados, especialmente en sus loables esfuerzos por investigar y difundir las ideas filosóficas producidas en Santo Domingo, desde sus antecedentes, pasando por los escritos de Antonio Sánchez Valverde y Andrés López de Medrano, hasta los filósofos de su propia generación, fallecidos todos en la segunda mitad del siglo xx.
}

Moreno Jimenes (como se citó en Moreno García, 2001, pp. 383-384.), exclama: “ $¡ O h$ América, que haces trizas las razas; dialectos las lenguas, murmullo perenne y vivificador el murmullo! (...). ¡Creadora de algo ni visto ni oído!".

Por momentos el poeta y el profeta parecen llegar a coincidir en la persona del creador del postumismo. Moreno Jimenes (como se citó en Moreno García, 2001), argumenta: "No importa que la América, norte y cima de la Humanidad, no existiera entonces: yo la crearía en mi obra, aun cuando, por ello me expusiera a obtener todos los dolores y recibir todos los infortunios". Sin embargo, hay un ideal que se ha apoderado de su vida y por eso dedica el tiempo necesario, como mensajero, para su cristalización. De ahí que el poeta asegure (como se citó en Moreno García, 2001):

América es la línea divisoria de los dos mundos en conflicto y en fuga. El que escucha el Mensaje de América no siente temores por la humanidad que ha de venir. Llevo más de veinte años labrando en mi silencio la piedra de la personalidad americana. En las de un porvenir preñado de auroras, se bañan mis ojos en estos momentos.

El fervor americanista, sin embargo, no impide advertir la funesta realidad que impide a nuestros pueblos cobrar conciencia del valor que encierran, frente a sí mismos y de cara a toda la humanidad: "Estos pueblos vacilan en definirse como si una fuerza herética los atara al coloniaje o al subdesarrollo. ¡Dominad los vientos! ¡Abrid las marejadas que os habían cerrado las sombras!" (como se citó en Moreno García, 2001).

Moreno Jimenes permanecía absorto, sumido en profundas reflexiones sobre el ser humano y su destino en un mundo dominado por la guerra, el afán de poder y una tecnociencia deshumanizada. De ahí surgen su acendrado americanismo y el abrazo de la poesía y el arte como fuerzas regeneradoras del ser humano. Moreno Jimenes colocó el arte y la religión en un plano de preeminencia espiritual. 
Conste que en 1936 la revista El Día Estético, nacida en 1928, reaparece con el subtítulo: "Con el estandarte del arte como Religión Universal”. Lo cual guarda vinculación con la consideración del arte como fuente o vía redentora, que años antes filósofos como Heidegger venían postulando y convirtiéndolo en objeto de sus reflexiones filosóficas.

Como explica Bárbara García (2001, p. 276), Moreno llega incluso a preguntarse si no será la poesía la que iniciará el renacimiento religioso del hombre. El poeta anuncia el nacimiento de un arte humanizado, orientador y universal que será la religión definitiva del hombre". En carta a su amigo Rafael Augusto Zorrilla exhorta: "Que la religión del arte despierte a los hombres"; y en otra carta le escribe a Manuel Mora Serrano: "Concebí el arte como Religión del Universo, es decir, substancial vínculo entre Dios y el Hombre". Moreno Jimenes (como citó Moreno García, 2001, p. 276). Bárbara Moreno lo interpreta así: "Él espera que el arte produzca una emancipación espiritual, un "milagro" suscitando un "despertar" en los hombres al mostrarles "la buena ruta", la que lleva a Dios" (Moreno García, 2001, p. 276).

\section{Repercusión del movimiento postumista en la poesía, literatura y pensamiento dominicanos}

La casi generalidad de los estudiosos del postumismo lo estiman como la primera escuela literaria dominicana, y una de las que registró mayor impacto en las generaciones subsiguientes, "Aun cuando surgiese con imperfecciones, que algunos sacan a la luz de cuando en vez con propósitos mezquinos, el Postumismo es nuestra gran escuela literaria. Con Moreno se estaba a favor o en contra, pero nadie podrá ignorar su evangelio poético" (Lantigua, 2020, s/f).

Se sabe que Bosch cultivó el cuento y la novela tomando como fuentes de inspiración la tierra y la penosa vida cotidiana de hombres y mujeres en el campo dominicano. Dicho autor confesó su admiración por los postumistas, pues uno y otros hablaban el lenguaje de la gente humilde. Pero ¿y qué decir de la poesía social de Pedro Mir, de la obra poética de Manuel del Cabral representada en su Compadre Mon, o de las motivaciones ideológicas de los poetas del 30 y del 40, lo cual queda demostrado en las obras de Rubén Suro y de Tomás Hernández Franco? En cuanto a Héctor Incháustegui Cabral, no solo valora la calidad literaria de Moreno Jiménez, sino que reconoce la repercusión de su legado en su propia obra.

Al pasar balance sobre la significación o impacto del postumismo hacia finales de la década del veinte, José Mármol (2019, pp. 71-91), asegura que:

sentará las bases de una poesía dominicana, en el fundamento estético y en la praxis del poema, con carácter de denuncia política y social, con un ideal americanista que impactó, incluso, a un líder político continental como Raúl Haya de la Torre (...). Así se sientan las bases de los poetas sociales de relevancia en nuestra evolución poética pertenecientes a los decenios del 30, con Los Nuevos, surgidos en 1936 y del 40, con voces preponderantes como las de Incháustegui Cabral, Hernández Franco, Mir, del Cabral y Domínguez Charro, entre otros.

Bruno Rosario Candelier resalta el mérito del postumismo al considerar que (Moreno García, 2001, p. 8) "inaugura para las letras dominicanas un nuevo estilo, una nueva sensibilidad y una nueva actitud ante el mundo". Puede sustentarse, además, que Moreno Jimenes se erigió en un pensador que abrazó el ideal de la América mestiza como portaestandarte de los valores más netamente humanos.

A pesar de que en sus inicios el postumismo y su fundador fueron motivos de desaire y hasta de rechazo por parte de la élite intelectual y literaria del país, con el transcurrir del tiempo se fue aquilatando su inestimable legado poético, literario y filosófico. Como poeta, Moreno Jimenes fue quien cabalgó con los ideales del postumismo hasta el ocaso de 
su dilatada existencia ${ }^{20}$. Por lo que puede afirmarse con Juan José Ayuso que dicho poeta (1980, p. 9) "establece la identidad nacional de la poesía", dado que "la pone a oler verduras, hortalizas y dulces del patio" (Ayuso, 1980, p. 9).

Andrés Avelino abrazó la causa postumista hasta inicios de los treinta. Para él, ya no representaba valor en términos literarios. Estaba centrado completamente en temas propios de la disciplina filosófica, sobre los cuales legó más de diez obras. Así pues, mientras Avelino abraza otra modalidad de saber, Moreno Jimenes, lanza en ristre, sigue apostando a la poesía; lo cual se advierte al expresar (como se citó en Lantigua, 1980, p. 145):

Como poeta cósmico yo estoy bien hallado en cualquier sitio y cualquier entidad, si me niegan el agua viviré del sudor de mi sangre; $y$ si la sangre me faltare, volveré sin dolor a la fuente de donde había partido. Me he embarcado en la carabela del espíritu y mi dicha mayor es realizar la obra rectificadora de América, en todos los medios y junto a todas las circunstancias. Si desde mi isla partida del Caribe, surge un rayo renovador que despierte a América y conmueva al mundo, yo pensaré que todas mis cuitas y todas mis tribulaciones jamás han sido vanas. Moreno Jimenes.

¿Exagera José Rafael Lantigua al calificar a Moreno Jimenes como (1980, p. 150), "el más grande poeta dominicano de todos los tiempos"? Se trata de un tema harto controversial.

Los aportes excepcionales de Moreno Jimenes han sido reconocidos con las máximas honras y reconocimientos que confiere el Estado dominicano y al menos tres universidades, Universidad Autonoma

\footnotetext{
${ }^{20}$ Para ahondar en su vida y en su obra cfr. Domingo Moreno Jimenes, Apóstol de la poesía, de José Rafael Lantigua; El recorrido poético de Domingo Moreno Jimenes, de Bárbara Moreno García; Antología poética de Domingo Moreno Jimenes, de Manuel Mora Serrano. Si bien este último libro es de carácter antológico, en sus páginas iniciales incluye un trabajo de capital importancia para aquilatar aspectos nodales de la biografía del poeta, de su producción poética y sobre la escuela literaria por él fundada.
}

de Santo Domingo (UASD), Universidad Nacional Pedro Henriquez Ureña (UNPHU) y Universidad Acción Pro-Educación y Cultura (UNAPEC. Otras entidades resaltaron y premiaron sus contribuciones al acervo literario nacional. Pero quizá una de las distinciones más apreciadas por el poeta, fue la tributada por el Taller Literario "César Vallejo" en la etapa finisecular, por provenir de la nueva generación que venía emulando, si bien no los lineamientos programáticos del postumismo, sí la pasión por la poesía, para cuya promoción se desplazaban por muchas ciudades del interior, al igual que el fundador del postumismo. Es probable que tal actitud misional dentro del arte poético criollo, solo se haya registrado dos veces en suelo dominicano: con los postumistas $\mathrm{y}$ con la generación de los ochenta del siglo $\mathrm{xx}^{2 \mathrm{r}}$.

\section{Conclusiones}

El 28 de marzo de 1921, en la ciudad de Santo Domingo, es proclamado oficialmente en La Cuna de América el postumismo como movimiento literario. Encabezado por tres jóvenes poetas: Domingo Moreno Jimenes, Andrés Avelino y Rafael Augusto Zorrilla, dicho movimiento se convertiría en lo que muchos consideran la principal escuela poético-literaria surgida en República Dominicana. $\mathrm{Al}$ percatarse de que el entorno sociocultural en que surge dicha tendencia le sería completamente hostil y que, por tanto, sus créditos o méritos solo tendrían reconocimiento póstumo, sus impulsores acordaron apoyar la idea de Andrés Avelino en nombrarlo postumismo.

No todos los movimientos literarios emiten una declaratoria formal y el postumismo no solo lo hizo, sino que tuvo particular esmero en enunciar

\footnotetext{
${ }^{21}$ José Rafael Lantigua (2020, s/p), distingue a los poetas organizados en el Taller "César Vallejo", destacando que después del movimiento postumista "sólo existe otro importante: la Generación de los 80. No hubo manifiesto alguno. Como casi siempre sucede, las coordenadas de ese grupo fueron diseñadas en sus escritos por su principal exponente: José Mármol (...) los ochentistas marcaron la raya de Pizarro frente a los setentistas. "Poética del ser": un entronque vitalísimo con la filosofía".
} 
los fundamentos teórico-ideológicos que les dieron origen. Estos postulados están consignados en sendos escritos fundacionales insertados por Moreno Jimenes y Andrés Avelino en el poemario Fantaseos, publicado por Avelino en 1921.

Ambos autores llegan a dos conclusiones básicas: a) El desprestigio moral e intelectual en que está sumergida Europa tras la Guerra Mundial de 1914, no le permite ya seguir ofreciendo orientaciones al resto del mundo, por lo que nuestro arte y pensamiento debe poner su mirada y punto de partida en nuestras potencialidades como hijos de América; b) El canon tradicional clasicista, caracterizado por las exigencias formales trazadas al ejercicio poético, debía ser reemplazado por otro que permita la expresión libre de las emociones.

Centrado en ambas premisas, el proyecto postumista se asume como la respuesta de sus fundadores a varios desafíos, el primero de los cuales fue verse provocados a crear nuevos formatos o recursos estéticos ajenos al clasicismo que abrieran causes nuevos a la esfera emocional sin la fijación de límite alguno a la hora de crear, específicamente un nuevo modo de hacer poesía donde los aspectos formales de rima y ritmo dejaran de ser requisitos sine qu a non para la composición poética.

Al transitar como cultivadores del arte poético por ruta diferente a lo trillado, tanto Moreno Jimenes como Andrés Avelino lograron concebir una categoría estética nueva que denominaron "acento emocional" que, al decir del primero, permitió concebir un nuevo modo de entender la belleza.

Vinculado al aspecto anterior, en la corriente postumista se encaró el reto de asumir un tipo de sensibilidad estética de nuevo cuño, que logró articularse exitosamente a dos disciplinas filosóficas: la axiología y la ética. Con esta convergencia de elementos teóricos, complementarios entre sí, el poeta se torna pensador crítico, logrando trascender lo formal o superficial y adentrarse en lo vital y cotidiano. Es así como en la escuela postumista se desecha lo universal por lo local, lo europeo por lo americano.
Es muy probable que José Vasconcelos, filósofo mexicano que visitó el país en la década en que surge el postumismo, dictando varias conferencias, y quien desde 1918 venía publicando libros sobre teoría estética, haya ejercido algún influjo en el litoral postumista.

Vasconcelos procuró configurar una dimensión estética de la existencia humana y consideró la emoción como una condición básica para comprender la naturaleza de las cosas. Estas conceptualizaciones de lo estético, más la consigna “ivolver a las cosas!” puesta en boga por la fenomenología de Edmundo Husserl, crean las condiciones de posibilidad teórica para el segundo desafío encarado por los postumistas, esto es, el poema como medio de expresión de las cosas del terruño y de la vida cotidiana.

La poesía cultivada en el país previo al postumismo se nutría mayormente de temas universales, extraídos casi siempre de la cultura europea; ahora, empero, el poema canta al paisaje, al propio suelo y a la vida sencilla de la gente. De súbito, la visión y la misión del poeta sufren un cambio radical, dando al traste con los esquemas rígidos consagrados por la tradición literaria. En un panorama como este, es explicable que los postumistas fueran criticados y hasta calumniados por autores anclados en el paradigma predominante anteriormente.

Que la producción poética de la tendencia postumista enfatice lo autóctono, implicará apreciaciones axiológicas nuevas y una cierta actitud ética donde el poeta asumirá compromiso de cara a su realidad social e histórica. Es aquí donde reside el tercer reto asumido por el movimiento postumista, que consiste en apostar por la autonomía intelectual de América, del país.

No sorprende, en consecuencia, la vehemencia con que Moreno Jimenes y Avelino se pronuncian en favor de un quehacer poético con temas y motivos nacionales, lo cual tiene como telón de fondo la ocupación de la nación por tropas foráneas, cuyas consecuencias las experimentó personalmente Moreno Jimenes. Por 
tal razón, el postumismo es pasible de una lectura en clave ideológico-política.

$\mathrm{Al}$ celebrarse el presente año su primer centenario, se estimó pertinente realizar un enfoque filosófico de dicha escuela poético-literaria, al tratarse de un movimiento que repercutió no solo entre los miembros del parnaso nacional, sino también entre los cultivadores de otros géneros literarios, como la novela. En la producción poética de Pedro Mir, Manuel del Cabral y Héctor Inchaustegui están presentes los influjos postumistas. De igual manera se pueden evidenciar en las novelas de Juan Bosch.

Las cabezas cimeras del postumismo fueron auténticos poetas y verdaderos pensadores. Moreno Jimenes fue quien mejor personalizó la nueva tendencia poética, aunque no debe olvidarse que en el ensayo Evangelio americano queda consagrado como un pensador de fuste. En Avelino, la filosofía opacó el poeta que habitaba en él, pero, con todo, persistió en crear hasta el final de sus días una corriente poética abstracta que dio en llamar poesía matemática. En realidad, ambos autores nos han legado sendas producciones literarias e intelectuales dignas de estudiarse con más profundidad.

Finalmente, el postumismo ha hecho honor al vocablo escogido para su denominación, pues como presagió Andrés Avelino en su Manifiesto de 1921, el índice se ha extendido "hacia el horizonte de los siglos". Y de tal forma que, un movimiento juvenil que no fue entendido ni justipreciado en su tiempo hoy ocupa uno de los sitiales más altos como expresión peculiar del arte poético y literario en República Dominicana.

\section{Referencias}

Alberdi, J. B. (1955). Obras completas (Vol. I). Fragmentos. Ed. De B. Canal Feijóo. Hachette.

Ayuso, J. J. (1980). Presentación. En J. R. Lantigua. Domingo Moreno Jimenes. Apóstol de la poesía (2a. ed.). Taller.
Baeza Flores, A. (1976). La poesía dominicana en el siglo XX (Primer Tomo). Colección Estudios, UCMM. Industrias Gráficas M. Pareja.

Beorlegui, C. (2010). Historia del pensamiento filosófico latinoamaericano. Una búsqueda incesante de identidad (3a. ed.). Deusto.

Céspedes, D. (1984). Ideas filosóficas, discurso sindical y mitos cotidianos en Santo Domingo. Taller.

Fernández Spencer, A. (2014), A orillas del filosofar (2a. ed.). Cielonaranja.

García, A. (1921), Fantaseos. Imp. La Cuna de América.

García Godoy, F. (2010), El Derrumbe (4ª. ed.). Comisión Permanente de Efemérides Patrias. Ediciones Librería La Trinitaria.

Henríquez Ureña, P. (2003), Obras completas (Tomo V 9). Escritos políticos, sociológicos y filosóficos. Secretaría de Estado de Cultura. Editora Nacional.

Lantigua, J. R. (4 de enero de 2020). Manifiestos literarios de la República Dominicana. http:// www.diariolibre.com/opinion/lecturas/manifiestos-literarios-de-la-republica-dominicana-AE16212367

Mármol, J. (2019). Tradición y ruptura en la poesía dominicana de los siglos XX y XXI. Dinámica de sus movimientos. Ciencia y Sociedad, 44(4), 71-91. https:/doi.org/10.22206/cys.2019.v4 4i4.pp71-91

Mármol, J. (1997). Ética del poeta. Amigo del Hogar. Martí, J. (1993). Nuestra América. En Zea, L. Fuentes de la cultura latinoamericana (pp.119-127). Fondo de Cultura Económica.

Mora Serrano, M. (1999). Antología poética de Domingo Moreno Jimenes. Santo Domingo, República Dominicana. Ediciones Librería La Trinitaria.

Moreno García, B. (2001). El recorrido poético de Domingo Moreno Jimenes. Datadruck.

Moreno Jimenes, D. (1975). Domingo Moreno Jimenes. Obras poéticas. Del Gemido a la fragua. Taller.

Moreno Jimenes, D. (1943). Antología minima. Santo Domingo, República Dominicana. 
Moreno Jimenes, D. (1921, Preliminar. En A. A. García. Fantaseos. Santo Domingo, República Dominicana: Imp. La Cuna de América.

Nacidit Perdomo, Y. (10 de agosto de 2015). Escribe Ylonka Nacidit Perdomo: Abigaíl Mejía, los intelectuales yel 16. Recuperado de http://www. acento.com.do/cultura/escribe-Ylonka-nacidit-persomo-abigail-mejía-los-intelectuales-y-el-16-8273975.html

Paz, O. (1986), Tiempo nublado. Seix Barral, S. A. Piña-Contreras, G. (1982). Doce en la literatura dominicana. UCPP.
Rosario Candelier, B. (2001). Introducción. En B. Moreno. El recorrido poético de Domingo Moreno Jimenes. Datadruck.

Rueda, M. (1999). Antología mayor de la literatura dominicana (siglos XIX-XX. Poesía I y Poesía II. Ediciones de la Fundación Corripio.

Sosa Ramos, A. (Julio de 2006). El humanismo iberoamericano de José Vasconcelos. Recuperado de www.ensayistas.org/critica/generals/ C-H/mexico/Vasconcelos.htm

Zea, L. (1976). El pensamiento latinoamericano. Ariel. 